\title{
Maatiainen ja modernit kaksitahoiset ohralajikkeet typenkäytön tehokkuusvertailussa Suomen kasvuoloissa
}

\author{
Susanna Muurinen ${ }^{1)}$ ja Pirjo Peltonen-Sainio ${ }^{1)}$ \\ ${ }^{1)}$ MTT, Kasvintuotannon tutkimus, 31600 Jokioinen, etunimi.sukunimi@mtt.fi
}

\begin{abstract}
Johdanto
Typpi on yksi tärkeimmistä kasviravinteista. Viljakasvit käyttävät 30-50\% annetusta lannoitetypestä hyödykseen (Rauan ja Johanson 1999). Kasvien typenkäytön tehokkuuden parantaminen on ajankohtainen haaste, kun tuotantomenetelmiä kehitettäessä pyritään edistämään ympäristön ekologista kestävyyttä. Tehostamalla kasvien typenottoa ja -käyttöä voimme vähentää huuhtoutumiselle alttiin, kasveilta hyödyntämättä jäävän typen määrää maaperässä. Perinnöllisesti tehokkaammin typpeä hyödyntävät lajikkeet parantavat myös viljelyn kannattavuutta.

Mollin ym. (1982) mukaan kasvien typenkäytön tehokkuus määritellään kasvin kykynä tuottaa jyväsatoa yhtä saatavilla olevaa lannoiteyksikköä kohden. Tämä typenkäytön tehokkuus (NUE) voidaan jakaa kahteen komponentiin, kasvin kykyyn ottaa typpeä maasta eli typenoton tehokkuuteen (UPE) ja edelleen kasvin kykyyn muuttaa otettu typpi jyväsadoksi eli typen hyväksikäytön tehokkuus (UTE). Vaikka aiemmin onkin todettu, ettei jalostuksella olisi ollut vaikutusta typenoton paranemiseen (Austin ym. 1980), typenoton tehokkuudessa on todettu olevan eroja lajikkeiden välillä ohralla (Gorny 2001) ja vehnällä (Le Gouis ym. 2000). Erot lajikkeiden välillä on havaittu eri olosuhteisiin sopeutuneissa lajikkeissa (Gorny 2001). Kaksi- ja kuusitahoisten ohrien typenoton tehokkuuden on todettu olevan samaa suuruusluokkaa keskenään (Le Gouis ym. 1999). Yleisesti typenoton tehokkuutta pidetään tärkeimpänä typenkäytön tehokkuuteen vaikuttavana ominaisuutena (Ortiz-Monasterio ym. 1997).

Typen hyväksikäytön tehokkuuden merkityksen on kuitenkin todettu korostuvan korkeammissa maaperäntyppi pitoisuuksissa ja sen on todettu lisääntyneen jalostuksen aikana merkittävästi (OrtizMonasterio ym. 1997). Tämän uskotaan johtuvan siitä, että typen kuljetus on vahvasti yhteydessä kuivaaineen kuljetukseen kasvissa, ja näin ollen typen kuljetusta voidaan tarkastella kahtena yksikkönä, satoindeksinä (HI) ja biomassantuoton tehokkuutena (BPE). Jalostuksen myötä satoindeksi on parantunut moderneilla lajikkeilla ja näin jalostuksen uskotaan parantaneen myös typen kuljetuksen tehokkuutta.

Tämän tutkimuksen tarkoituksena oli määrittää typenkäytön tehokkuus Suomen kasvuoloissa kaksitahoisella ohralla sekä arvioida typenkäytön tehokkuuteen vaikuttavien eri komponenttien osuutta ja jalostuksella aikaansaatuja muutoksia.
\end{abstract}

\section{Aineisto ja menetelmät}

Koe suoritettiin vuosina 2001-2003 MTT Maa- ja elintarviketalouden tutkimuskeskuksessa Jokioisilla. Kokeeseen oli valittu kaksitahoisista ohrista maatiaislajike ja kaksi modernia lajiketta. Koejärjestelynä oli satunnaistettujen lohkojen koe; pääruutuna oli lannoitus $(0 \mathrm{kgN} / \mathrm{ha}$ ja $90 \mathrm{kgN} / \mathrm{ha}) \mathrm{ja}$ osaruutuna lajike. Nollaruudulla voitiin havainnoida maasta vapautuvan typen määrä. Lannoitteena käytettiin Pellon Y5, NP-K: 20-5-4. Uurainen on 1922 markkinoille laskettu pitkäkortinen maatiaislajike, Inari 1994 markkinoille tullut Suomessa mallasohranakin käytetty kotimainen lajike ja Scarlett 1998 markkinoille tullut Saksalainen mallasohralajike. Kokeet kylvettiin 10. toukokuuta 2001, 29. huhtikuuta 2002 ja 13. toukokuuta 2003. Tasaisen kasvun ja normaalin typenoton ylläpitämiseksi koekenttiä sadetettiin vuosina 2001 ja 2002. Rikkakasvit ja lehtilaikkutaudit torjuttiin kemiallisesti. Koska mukana ollut maatiaislajike oli korreltaan pitkä ja lakoontui helposti sen mahdollisimman pitkään pystyssä pysyminen pyrittiin varmistamaan 'tukiaidalla' vuosina 2001 ja 2002. Lakoontumista kuitenkin esiintyi vuonna 2003 myös muilla lajikkeilla.

Typen käytön tehokkuuden laskemisessa käytettiin tuleentuneita kasvinäytteitä, jotka oli kerätty ruuduista juuri ennen puintia. Koeruuduilta kerättiin satunnaisesti 20 kasviyksilön maanpäällinen massa. Näytteet fraktioitiin pää- ja sivuversoihin ja edelleen lehtiin, korsiin ja tähkiin. Näytteitä kuivattiin $60^{\circ} \mathrm{C}$ lämpötilassa kaksi vuorokautta, jonka jälkeen kuiva-aine punnittiin ja näytteet jauhettiin jatkomääritystä varten. Näytteistä määritettiin typpipitoisuus Leco-autoanalyyserillä. Typpipitoisuudet, satoindeksi ja typenkäytön tehokkuuteen liittyvät laskennalliset ominaisuudet muodostettiin käyttäen saatuja typpipitoisuuksia ja näytteiden kuiva-aineita seuraavin yhtälöin:

Satoindeksi $(\mathrm{HI})=$ jyvä sato $\left(\mathrm{g} \mathrm{m}^{-2)} /\right.$ kasvin fytomassa $\left(\mathrm{g} \mathrm{m}^{-2}\right)$

Biomassan tuoton tehokkuus $\left(\mathrm{g} \mathrm{g} \mathrm{N}^{-1}\right)(\mathrm{BPE})=$ kasvin fytomassa $\left(\mathrm{g} \mathrm{m}^{-2}\right) /$ kasvin typpimäärä $\left(\mathrm{g} \mathrm{N} \mathrm{m}^{-2}\right)$ 
Typen hyväksikäytön tehokkuus $\left(\mathrm{g} \mathrm{g} \mathrm{N}^{-1}\right)(\mathrm{UTE})=\mathrm{HI} * \mathrm{BPE}$

Typen oton tehokkuus $(\mathrm{UPE})=[$ kasvin typpimäärä (N90) - kasvin typpimäärä nollaruudussa] / lannoitteen typpimäärä

Typen käytön tehokkuus $\left(\mathrm{g} \mathrm{gN}^{-1}\right)(\mathrm{NUE})=\mathrm{UTE} * \mathrm{UPE}$

Tilastollisessa analyysissä käytettiin SAS-ohjelmaa (PROC MIXED).

\section{Tulokset ja tulosten tarkastelu}

Vuodet erosivat lämpötilakertymältään ja sademääriltään toisistaan. Vuosi 2002 oli koejakson kuivin, sen kasvukauden aikainen sademäärä oli pienin kolmesta tutkimusvuodesta. Kasvukaudenaikaiselta lämpötilasummaltaan vuoden 2001 kertymä oli pienin. Suurin lämpötilakertymä oli vuonna 2003.
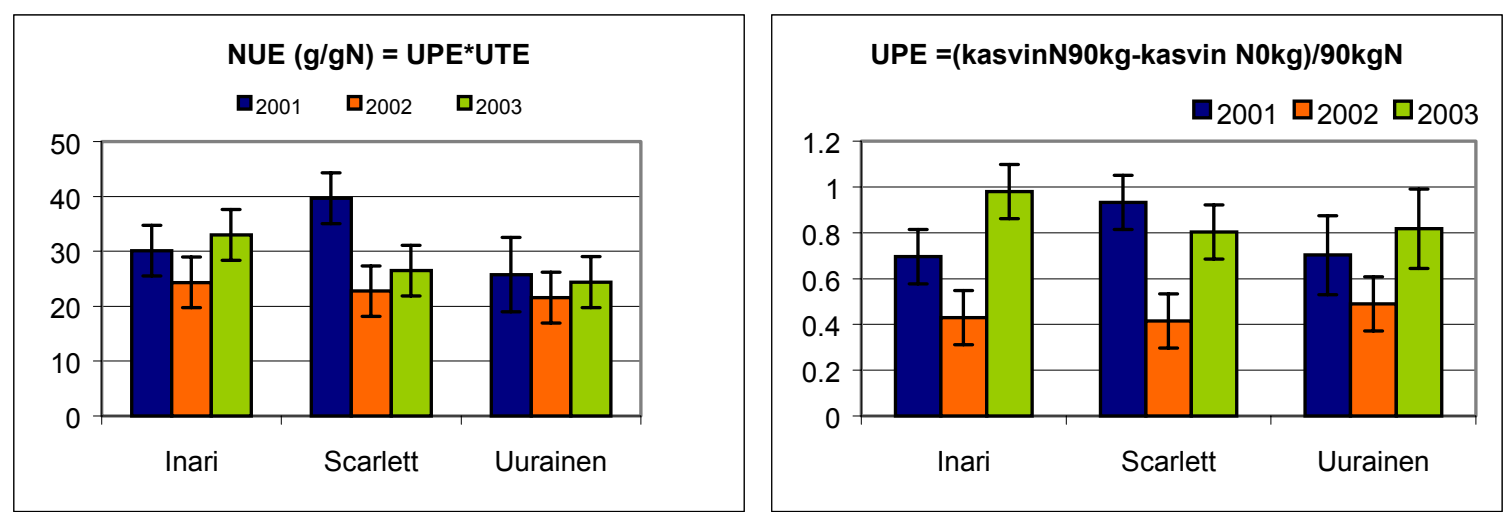

Kuva 1. Typenkäytön tehokkuus (NUE) ja typenoton tehokkuus (UPE) kolmena vuonna kahdella modernilla lajikkeella (Inari ja Scarlett) ja Uurainen-maatiaislajikkeella.

Vuoden 2002 NUE-arvot olivat kaikilla lajikkeilla vuosia 2001 ja 2003 alhaisempia. Scarlettin ja Inarin NUE-arvot olivat jokaisena vuonna Uuraista suuremmat. Uuraisen NUE oli kuitenkin muihin lajikkeisiin nähden stabiilimpi. Lajikkeiden ja vuosien väliset erot eivät olleet tilastollisesti merkitseviä. Tämä osoittaisi, ettei Suomen ja Pohjois-Euroopan kasvuoloissa typenkäyttö ole tehostunut, vaikka lajikkeiden sadot ovatkin huomattavasti kasvaneet. Vaikka lajikkeilla ei ollutkaan tilastollisesti merkitsevää eroa NUE-arvoissa, voitiin havaita suuntaus, että kaksitahoisten ohrien NUE-arvoon vaikuttaa Suomen kasvuoloissa voimakkaimmin kasvien kyky käyttää jo ottamaansa typpeä kasvuun kuin varsinainen kasvin typenotto maasta

Typenkäytön tehokkuuteen vaikuttavista ominaisuuksista UPE oli selvästi alhaisin kaikilla lajikkeilla vuonna 2002. Ortiz-Monasterion ym. (1997) mukaan alhaisissa typpioloissa UPE on UTEa merkittävämpi ominaisuus viljakasveilla. Vuoden 2002 typpitasot olivat kokeessa sadetuksesta huolimatta alhaiset. Keväällä mitatuista maaperänäytteistä vuoden 2002 typpimäärät olivat alhaisimmat (tulosta ei esillä) ja kasvien nollaruuduista ottamat typpimäärät jäivät myös vähäisiksi. Lajikkeiden välillä ei ollut tilastollisesti merkitseviä eroja, mutta vuonna 2002 Uuraisen UPE arvo oli jonkin verran korkeampi kuin Inarilla ja Scarlettilla. Typenoton tehokkuuden parantamisen kannalta vuodet 2001 ja 2003 ovat osoitus lajikkeiden todellisesta kyvystä ottaa typpeä maasta ja niiden vähäisistä eroavaisuuksista. Kun maasta vapautuu typpeä runsaasti rinnan lannoitetypen kanssa, hyvä UPE-ominaisuus kasvissa olisi suotava huuhtoutumiselle alttiin typen välttämiseksi. Jalostus ei kuitenkaan näyttäisi parantaneen merkittävästi kaksitahoisen ohran typenottoa näissä olosuhteissa.

Kaikkien lajikkeiden UTE oli lannoituksesta riippumatta suurin vuonna 2002. Heikoin UTE oli kaikilla lajikkeilla vuonna 2003. Uuraisella oli Inaria ja Scarlettia alhaisempi UTE kaikkina koevuosina. Inarin ja Scarletin UTE-arvot eivät poikenneet toisistaan merkittävästi vuosina 2001 ja 2003.Vanhat ja uudet lajikkeet näyttävät siis eroavan toisistaan UTE-ominaisuuden suhteen. Tarkasteltaessa UTE-arvoa lähemmin havaittiin, että satoindeksi vaikutti siihen biomassan tuoton tehokkuutta enemmän. Tätä havaintoa tukevat myös aiemmin esitetyt tulokset vehnällä (Calderini ym.1995).

BPE vaihteli myös vuosien välillä, alhaisin se oli 2003 sekä $0 \mathrm{kgN} / \mathrm{ha}$ että $90 \mathrm{kgN} / \mathrm{ha}$ lannoitustasoilla. Korkeimmillaan arvot olivat kaikilla lajikkeilla vuonna 2002. Vuoden vaikutus BPEn ei kuitenkaan ollut tilastollisesti merkitsevä. 
Taulukko 1. Typpilannoituksen ja lajikkeen vaikutus typen hyväksikäytön tehokkuuteen ja siihen liittyviin osakomponentteihin.

\begin{tabular}{|c|c|c|c|c|c|c|c|c|c|}
\hline \multirow[b]{2}{*}{ Käsittely } & \multicolumn{3}{|c|}{ UTE } & \multicolumn{3}{|c|}{ BPE } & \multicolumn{2}{|c|}{$\mathrm{HI}$} & \multirow[b]{2}{*}{2003} \\
\hline & 2001 & 2002 & 2003 & 2001 & 2002 & 2003 & 2001 & 2002 & \\
\hline \multicolumn{10}{|c|}{ Typpi (N) kg ha-1 } \\
\hline 0 & 48.8 & 57.2 & 39.5 & 96.1 & 114.1 & 80.6 & 50.8 & 50.1 & 49.0 \\
\hline \multirow[t]{2}{*}{90} & 41.9 & 51.9 & 30.3 & 87.0 & 105.7 & 66.5 & 48.3 & 49.1 & 45.8 \\
\hline & $* * *$ & $* * *$ & $* * *$ & $* *$ & $* *$ & $* * *$ & $* * *$ & * & $* * *$ \\
\hline \multicolumn{10}{|l|}{ Lajike (L) } \\
\hline Inari & 47.6 & 59.6 & 37.7 & 93.5 & 114.8 & 72.9 & 50.9 & 52.0 & 51.7 \\
\hline Scarlett & 47.2 & 57.1 & 39.0 & 86.9 & 107.4 & 73.1 & 54.3 & 53.2 & 53.2 \\
\hline \multirow[t]{2}{*}{ Uurainen } & 41.2 & 47.0 & 28.0 & 94.2 & 107.6 & 74.5 & 43.6 & 43.7 & 37.3 \\
\hline & $* *$ & $* * *$ & $* * *$ & $* *$ & $* *$ & & $* * *$ & * & ** \\
\hline $\mathrm{N} \times \mathrm{L}$ & & & * & * & & & & * & 0 \\
\hline
\end{tabular}

UTE = typen hyväksikäytön tehokkuus, $\mathrm{BPE}=$ biomassan tuoton tehokkuus, $\mathrm{HI}=$ satoindeksi ${ }^{* * *}=\mathrm{P}<0.001,{ }^{* *}=\mathrm{P}<0.01,{ }^{*}=\mathrm{P}<0.05$ ja o $=\mathrm{P}<0.10$

Sen sijaan lannoituksella oli vaikutusta lajikkeen vasteisiin: BPE oli pienin kaikilla lajikkeilla $90 \mathrm{kgN} / \mathrm{ha}$ lannoituksella ja Scarlettin BPE-arvo poikkesi muista lajikkeista. Nolla-lannoitustasolla lajikkeiden väliset erot olivat pienempiä, mutta Inarin BPE oli Scarlettin ja Uuraisen arvoja suurempi. Tämän perusteella Scarlett tuottaa typpikilolla biomassaa vähemmän kuin Inari ja Uurainen.

Lannoituksella oli vaikutusta myös toiseen UTEn osaominaisuuteen eli satoindeksiin. Nolla lannoituksella satoindeksi oli korkeampi kuin $90 \mathrm{kgN} / \mathrm{ha}$ lannoitustasolla. Uuraisen satoindeksi oli huomattavasti muita alhaisempi ja Scarlettin oli korkeampi lannoitustasosta riippumatta. Vuodella oli vähän vaikutusta lajikkeiden satoindekseihin.

\section{Johtopäätökset}

Kaksitahoisen ohran typenkäytön tehokkuudessa ei tämän tutkimuksen perusteella näyttäisi tapahtuneen muutosta Suomen kasvuoloissa 1900-luvulla. Uudet lajikkeet tuottavat kylläkin enemmän jyviä kasvin ottamaa typpikiloa kohti lähinnä suuremman satoindeksin ansiosta. Löytämällä eroja kasvin typen otossa ja oton tehokkuutta lisäämällä voitaisiin typenkäytön tehokkuutta koko kasvissa parantaa.

\section{Kirjallisuus}

Austin, R.B., Bingham, J., Blackwell, R.D., Evans, L.T., Ford, M.A., Morgan, C.L. \& Taylor, M.1980. Genetic improvements in winter wheat yield since 1900 and associated physiological changes. J. Agric. Sci. 94: 675-689.

Calderini, D.F., Torres-Leon, S. \& Slafer, G.A. 1995. Consequences of wheat breeding on Nitrogen and phosphorus yield, grain nitrogen and phosphorus concentration and associated traits. Annals of Botany. 76:315-322. Gorny, A.G. 2001. Variation in utilization efficiency and tolerance to reduced water and nitrogen supply among wild and cultivated barleys. Euphytica. 117:59-66.

Le Gouis, J., Delebarre, O., Beghin, D., Heumez, E. \& Pluchard, P. 1999. Nitrogen uptake and utilization efficiency of two-row and six-row winter barley cultivars grown at two N levels. Eur. J. Agron. 10: 73-79.

Le Gouis, J., Beghin, D., Heumez, E. \& Pluchard, P. 2000. Genetic differences for nitrogen uptake and nitrogen utilization efficiencies in winter wheat. Eur. J Agron. 12: 163-173.

Moll, R.H., Kamprath, E.J. \& Jackson, W.A. 1982. Analysis and Interpretation of Factors Which Contribute to Efficiency of Nitrogen Utilization. Agron. J. 74: 562-564.

Ortiz-Monasterio, R.J.I., Sayre, K.D., Rajaram, S. \& McMahon, M. 1997. Genetic Progress in wheat yield and nitrogen use efficiency under four N rates. Crop Sci 37: 898-904.

Rauan, W.R. \& Johanson,G.V. 1999. Improwing Nitrogen Use Efficiency for Cereal Production. Agron. J. 91: $357-$ 363. 